\title{
Effect of Ring Isomerism on Spectral and Antimicrobial Studies of Sm (III) Juglonates
}

\author{
Pritam Shinde ${ }^{1}$, Smita Nilakhe ${ }^{2}$, Vishwambhar Shinde ${ }^{1}$, B.A. Kulkarni ${ }^{1}$ \\ V.R. Sapre ${ }^{2}$, M. P. Wadekar ${ }^{1 *}$ \\ ${ }^{I}$ Department of Chemistry, Yashwantrao Mohite College, Bharati Vidyapeeth University, Pune,India \\ ${ }^{2}$ Department of Microbiology, Yashwantrao Mohite College, Bharati Vidyapeeth University, Pune,India
}

\begin{abstract}
Sm(III) Chelates of isomeric juglones i.e of lawsone, juglone, phthiocol and plumbagin have been synthesized. Molecular structures of these isomeric chelates are investigated with the help of thermogravimetry, infrared, electronic spectroscopy and microanalysis. The antimicrobial activity of ligands and the chelates is tested. The results of structural investigations and antimicrobial activity are compared to explore the nature and consequences of ring isomerism on the structural characteristics and antimicrobial activity of these isomeric chelates.
\end{abstract}

Key words: Sm(III), lawsone, juglone phthiocol, plumbagin, spectral, antimicrobial studies.

\section{Introduction}

Juglones which are hydroxyl derivatives of 1,4 naphthoquinones constitute a typical class of ligands. All juglones possess powerful chelating ability, due to which they can interact with most of the metals forming a huge number of metal chelates which recognized as metal juglonates.<smiles>O=C1C=C(O)C(=O)c2ccccc21</smiles>

Lawsone (LW)<smiles>O=C1C=CC(=O)c2c(O)cccc21</smiles>

Juglone (JU)<smiles>CC1=C(O)C(=O)c2ccccc2C1=O</smiles>

Phthiocol (PH)<smiles>CC1=CC(=O)c2c(O)cccc2C1=O</smiles>

Plumbagin (PL)

Fig-1 Parent members of juglone

The important members of Juglone series under study are shown in the Fig-1.Some of the interesting aspects of juglones include (a)Natural occurrence in medicinal plants as their active constituents[1] (b) Exhibition of isomerism due to change of position of hydroxyl group on naphthoquinone moity.This results in an interesting type of isomerism which is called as ring isomerism[2] after chelation with metals(c) Strong 'Intermolecular and Intramolecular' hydrogen bonding[3,4] is a special feature of Juglones which accounts for their powerful microbiological[5]activities. These ligands also possess pharmacological [6], allelopathic[7] entomological[8]and anticancer activity[9].Due to versatile nature of juglones study of metal complexes of these ligands is a subject of interest for researchers for past fifty years.

Structural characterization of lanthanide complexes is a current need because lanthanide complexes especially samarium complexes have gained significant attention because of their variety of applications as catalyst in selective hydroboration[10],as electroluminescent material[11],antimicrobial agents[12,13] anticancer and antiproliferative agents[14,15]Some lanthanide chelates of hydroxy naphthoquinones and their derivatives are reported by Kelkar[16],Jagtap[17-19] Khandagale[20],Varpe[21]. TheCytotoxic effects of samarium and some lantanide plumbaginates are reported by M. Tan[22] and Chen Z.[23].In present communication we are reporting isomeric chelates of $\mathrm{Sm}(\mathrm{III})$ with lawsone(LW), juglone(JU), phthiocol(PH) and plumbagin(PL) which are called Sm(III) Lawsonate, Juglonate,Phthiocalate and Plumbaginate to examine effect of five and six membered ring formation after chelation on their structural and antimicrobial properties.

\subsection{Synthesis of ligands}

\section{Materials And Methodes}

Juglone and phthiocol were prepared by following the method suggested by Radt[24] and Fisher[25] respectively while plumbagin was the commercial product obtained from Bio Organics, Madras (India).

\subsection{Synthesis of Chelates}

The methanolic solutions of the ligands (lawsone, juglone $0.522 \mathrm{gm}$ phthiocol and plumbagin $0.564 \mathrm{gm}, 3 \mathrm{mmol})$ and aqueous solution of samarium chloride $(0.261 \mathrm{gm}, 1 \mathrm{~m}$ mol) were used. The Sm(III) 
phthiocolates and plumbaginates were precipitated by mixing the corresponding metal ion solution and ligand solution taken in the proportion of about 1:3 and the $\mathrm{pH}$ was adjusted to 4-5 for phthiocolates and 6-7 for plumbaginates by aq.ammonia solution (10\%) and reaction mixture was refluxed (with stirring) for 3 hours in oil bath at $60^{\circ} \mathrm{C}$. After cooling the products were filtered and dried in a vacuum desiccators.

\subsection{Instrumental techniques}

The chelates were analyzed micro analytically using Thermo Finnigan CHNS and O analyzer for obtaining the percentage of carbon, hydrogen and residue (as metal oxide MO). The thermograms of the chelates were recorded on DTG-60 Simultaneous DTA-TG apparatus Shimadzu model and the solid state infrared spectra of ligands and metal chelates are recorded in $\mathrm{KBr}$ (discs) in the region $4000-450 \mathrm{~cm}^{-1}$ on Thermo Scientific (Nicolet iS5) spectrophotometer. The electronic spectra of ligands as well as their chelates were recorded in $\mathrm{KBr}$ disc in the region 200-1100 nm against pure $\mathrm{KBr}$ disc as the reference on Shimadzu U.V300 double spectrophotometer. $1 \mathrm{mg}$ of the sample was mixed in $100 \mathrm{mg}$ of spectroscopic $\mathrm{KBr}$ and transparent pellets of $0.1 \mathrm{~mm}$ thickness were obtained for recording the spectra.

\section{Results And Discussion}

The molecular composition of the chelates, which has been established on the basis of elemental analysis and thermogravimetry and their general physical properties are given in Table-1.They show attractive intense visible colors in solid state. The Lawsonates and phthiocolates possess intense orange or red color while Juglonates and plumbaginates possess dark violate or brown shades.

Table.1: Analytical Data of Sm(III) chelates of Lawsone, Juglone,Phthiocol and Plumbagin

\begin{tabular}{cllllll}
\hline $\begin{array}{l}\text { Sr. } \\
\text { No }\end{array}$ & Empirical Formula & Color & Yield(\%) & \multicolumn{2}{l}{ Elemental Analysis: Found (Calcd.) } \\
& & & & $\mathrm{C}$ & $\mathrm{H}$ & $\mathrm{M}(\mathrm{as} \mathrm{MO})$ \\
\hline 1. & $\mathrm{Sm}(\mathrm{LW})_{3} 2 \mathrm{H}_{2} \mathrm{O}$ & Deep Red & 70.11 & 52.28 & 2.88 & 25.01 \\
& $\mathrm{Sm} . \mathrm{C}_{30} \mathrm{H}_{19} \mathrm{O}_{11}$ & & & $(51.049)$ & $(2.713)$ & $(24.76)$ \\
\hline 2. & $\mathrm{Sm}(\mathrm{JU})_{3} 2 \mathrm{H}_{2} \mathrm{O}$ & Dark Violet & 63.22 & 52.03 & 2.44 & 24.00 \\
& $\mathrm{Sm} . \mathrm{C}_{30} \mathrm{H}_{19} \mathrm{O}_{11}$ & & & $(51.049)$ & $(2.713)$ & $(24.76)$ \\
\hline 3. & $\mathrm{Sm}(\mathrm{PH})_{3} .2 \mathrm{H}_{2} \mathrm{O}$ & Orange & 68.85 & 56.79 & 2.20 & 23.63 \\
& $\mathrm{Sm} . \mathrm{C}_{33} \mathrm{H}_{25} \mathrm{O}_{11}$ & & & $(53.00)$ & $(3.37)$ & $(23.31)$ \\
\hline 4. & $\mathrm{Sm}(\mathrm{PL})_{3} .2 \mathrm{H}_{2} \mathrm{O}$ & Dark Brown & 67.38 & 55.79 & 2.20 & 26.63 \\
& $\mathrm{Sm} . \mathrm{C}_{33} \mathrm{H}_{25} \mathrm{O}_{11}$ & & & $(53.00)$ & $(3.37)$ & $(23.31)$ \\
\hline
\end{tabular}

LW: Lawsone JU: Juglone PH: Phthiocol PL: Plumbagin

\subsection{Thermal study}

Determination of the percentage of water molecules and confirmation of the percentage of metal oxide were done through thermogravimetry [26]. The thermal decomposition curves recorded in nitrogen show a two to three step weight loss pattern. In the initial step that occurs in the temperature range $0-180^{\circ} \mathrm{C}$, the weight loss corresponds to loss of two water molecules. In the subsequent steps, involving temperature up to $650^{\circ} \mathrm{C}$, oxidative decomposition of the ligands takes place resulting in the final product and lanthanide metal oxide $\mathrm{Sm}_{2} \mathrm{O}_{3}$. The procedural and final decomposition temperatures are lower for phthiocolates than plumbaginates indicating that the Juglonates and plumbaginates are thermally more stable than lawsonates and phthiocolates respectively[2]. Therefore juglonates and plumbaginates involving six member ring have stronger intermolecular forces than those in lawsonates and phthiocolates involving five member ring.

\subsection{Infrared spectroscopy}

The IR spectra of the ligands and their chelates are shown in Fig-2 and significant IR peaks are summarized in Table-2.

Table-2 Significant IR peaks of juglones and their Chelates

\begin{tabular}{|c|c|c|c|c|c|c|}
\hline \multirow[t]{2}{*}{ Sr.No. } & \multirow[t]{2}{*}{ Compound } & \multirow{2}{*}{$\begin{array}{l}\mathbf{v}(\mathrm{OH}) \\
\left(\mathrm{cm}^{-1}\right)\end{array}$} & \multicolumn{2}{|c|}{$v(C=O)\left(\mathrm{cm}^{-1}\right)$} & \multirow{2}{*}{$\begin{array}{l}v(C-O) \\
\left(\mathrm{cm}^{-1}\right)\end{array}$} & \multirow{2}{*}{$\begin{array}{l}-\mathrm{CH}_{3} \\
\left(\mathrm{~cm}^{-1}\right)\end{array}$} \\
\hline & & & Chelated & Free & & \\
\hline 1 & Lw & 3170 & 1592 & 1678 & 1214 & - \\
\hline 2 & Sm-Lw & 3421 & 1574 & 1653 & 1221 & - \\
\hline 3 & JU & 3145 & 1643 & 1664 & 1225 & - \\
\hline 4 & Sm-JU & 3421 & 1595 & 1635 & 1239 & - \\
\hline 5 & $\mathrm{PH}$ & 3335 & 1590 & 1656 & 1208 & 2942 \\
\hline 6 & Sm-PH & 3367 & 1542 & 1559 & 1232 & 2926 \\
\hline 7 & PL & 3174 & 1644 & 1663 & 1230 & 2965 \\
\hline 8 & Sm-PL & 3433 & 1613 & 1643 & 1252 & 2963 \\
\hline
\end{tabular}




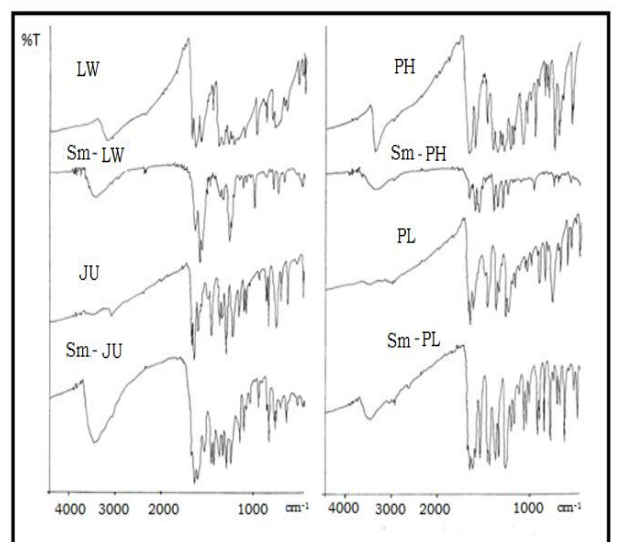

Fig -2. Infrared spectra of Isomeric Juglones and Sm-Chelates.

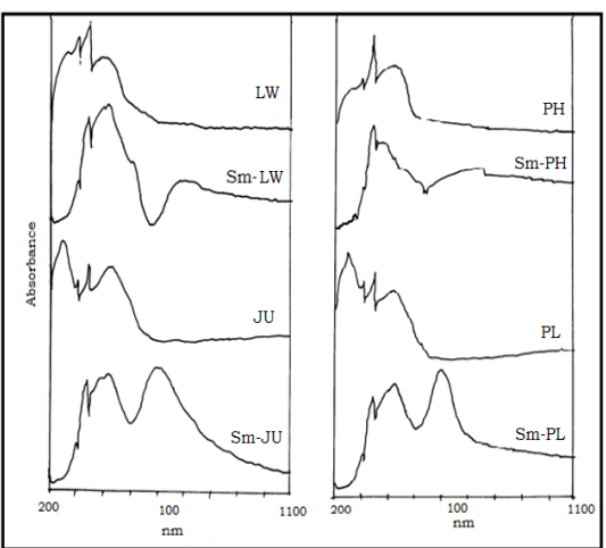

Fig-3. Electronic spectra of Isomeric Juglones and Sm-Chelates.

These peaks are examined particularly to assess the effect of chelation and ring isomerism on their peak position and peak intensity.

\subsubsection{O-H Stretching Frequency:}

The $\mathrm{O}-\mathrm{H}$ stretching frequency is observed in the ligands, in the form of a broad band of medium intensity in the range of $3145-3335 \mathrm{~cm}^{-1}$ [27]. This frequency is expected to be absent in all chelates due to chelation but its place is taken by $\mathrm{O}-\mathrm{H}$ vibrational modes arising due to the association of lattice or coordinated water. The $\mathrm{O}-\mathrm{H}$ stretching frequency arising from water molecule appears at $3421 \mathrm{~cm}^{-1}$ for Lawsonate and Juglonate. For phthiocolate and plumbaginate it appears at $3367 \mathrm{~cm}^{-1}$ and $3433 \mathrm{~cm}^{-1}$ respectively.

\subsection{2 $\mathrm{C}=$ O Stretching Frequency:}

There are two non equivalent $\mathrm{C}=\mathrm{O}$ bonds in all the ligands and chelates. One of these which is adjacent to $-\mathrm{OH}$ group is directly involved either in hydrogen bonding in the free ligand or in chelate formation in their metal chelates. Hence, these bonds are characterized as 'chelated $\mathrm{C}=\mathrm{O}$ ' bond, while for other it is characterized as 'non-chelated' or 'free $\mathrm{C}=\mathrm{O}$ ' bond. Corresponding IR frequencies are assigned as chelating $\mathrm{C}=\mathrm{O}$ and nonchelating $\mathrm{C}=\mathrm{O}$ stretching frequencies.

As a result of chelation, the chelated $\mathrm{C}=\mathrm{O}$ stretching frequency is shifted to lower frequency region indicating that bonding with metal is through chelated carbonyl oxygen[28] in all four chelates. Similarly the non-chelating $\mathrm{C}=\mathrm{O}$ frequencies are shifted to lower wave number. This suggests that although, the free $\mathrm{C}=\mathrm{O}$ bond is not directly involved in the chelation, there seems to be some mechanism due to which withdrawal of electron density from this $\mathrm{C}=\mathrm{O}$ bond takes place, resulting a large red shift.

when chelated $\mathrm{C}=\mathrm{O}$ frequency of the isomeric pairs is compared it is found that frequencies of juglonates and plumbaginates are observed at higher wavelengths as compared to lawsonates and phthiocolates indicating their greater strength in the respective chelates.

\subsubsection{C-O Stretching Frequency:}

This is another important frequency which is involved in chelation. In the juglone and plumbagin, C-O stretching frequency is observed at higher wave number $(1225-1230 \mathrm{~cm}-1)$ as compare to lawsone and phthiocol(1214-1208) respectively indicating comparatively stronger bonding. The large red shifts indicate $\mathrm{C}-\mathrm{O}$ bond becomes stronger in chelates. When this observation is coupled with the weakening of the free $\mathrm{C}=\mathrm{O}$ bond, it suggests that there might be a delocalization of electron density over the region connected by free $\mathrm{C}=\mathrm{O}$ bond and chelated $\mathrm{C}-\mathrm{O}$ bond due to which there is a transfer of electron density from the free $\mathrm{C}=\mathrm{O}$ bond to chelated C-O bond as suggested by Kodolikar [29].

The greater strength of chelated $\mathrm{C}=\mathrm{O}$ and $\mathrm{C}-\mathrm{O}$ in plumbaginates indicate that the six membered ring in plumbaginates is more stable than five membered ring in phthiocolates. A comparison of the stretching frequencies corresponding to that of chelated $\mathrm{C}=\mathrm{O}$ and $\mathrm{C}-\mathrm{O}$ bond in these isomeric chelate provides an evidence to assess the relative stability of five membered ring and six membered ring.

\subsection{Electronic Spectroscopy}

The spectra of all the ligands and their chelates are shown in Fig.-3 and significant absorption maxima are given in Table-3. Electronic spectra of 1,4 naphthoquinones are interpreted by previous workers[30].The electronic spectra of lawsone, juglone, phthiocol, plumbagine in polar as well as non polar solvent have been studied in detail along with their C-3 substituted derivatives to examine the effect of C-3 substitution[21,26].. 
The spectra of lawsone, juglone, phthiocol and plumbagin consist of three principal bands which are called as benzenoid electron transfer (BET), quinonide electron transfer (QET) with medium intensity and $n \rightarrow \pi^{*}$, which is comparatively broad.

In the present work a comparative study of the electronic spectra of these selected ligands and their samarium(III) juglonates in solid state is carried out mainly to examine effect of 'ring isomerism' on these spectra. These chelates show intense colours in solid state which are stable towards light, moisture, atmospheric air and variations in temperature. It is further found that colour of the chelates is characteristics feature of this chelate in solid state which is reduced when they are dissolved (partially) in solvents.

\subsubsection{Effect of Chelation:}

A comparison of spectra of chelate with the spectra of their ligand shows that there is a general resemblance between these spectra. Thus, spectra of ligands and chelate consist of three principle bands. The first being due to the BET, the second due to the QET and last band is expected to occur due to mixing of $\mathrm{n} \rightarrow \pi^{*}, \mathrm{f}-\mathrm{f}$ transition and charge transfer transition as a result of chelation with the metal ions.

Table 3. Absorption maxima of solid state electronic spectra of Isomeric Juglones and Sm-Chelates.

\begin{tabular}{|c|c|c|c|c|}
\hline \multirow[t]{2}{*}{ Sr.No. } & \multirow[t]{2}{*}{ Compound } & \multicolumn{3}{|c|}{ Principle band wavelength } \\
\hline & & BET $\lambda$ nm. & QET $\lambda$ nm. & $\begin{array}{l}\mathbf{n} \rightarrow \pi^{*} / \mathbf{L} \rightarrow \mathbf{M} / \\
\text { transition } \lambda \mathbf{n m} .\end{array}$ \\
\hline 1. & LW & 260 & 343 & 394 \\
\hline 2. & Sm-LW & 343 & 418 & 694 \\
\hline 3. & JU & 247 & 367 & 425 \\
\hline 4. & Sm-JU & 343 & 397,422 & 599 \\
\hline 5. & $\mathrm{PH}$ & 265 & 344 & 418 \\
\hline 6. & $\mathrm{Sm}-\mathrm{PH}$ & 343 & 380 & 750 \\
\hline 7. & PL & 248 & 363 & 407 \\
\hline 8. & Sm-PL & 343 & 422 & 594 \\
\hline
\end{tabular}

In all four chelates the first band BET becomes of medium intensity and it is shifted to higher wavelength by (83-78) $\mathrm{nm}$ in five membered Sm(III) Lawsonate and phthiocolate and by (96-95) $\mathrm{nm}$ in Sm(III) juglonate and plumbaginate. These shift in juglonate and plumbaginate are greater than lawsonate and phthiocolate.The second band due to QET shows increase in intensity after chelation and is shifted to higher wavelength.This shieft is by $81-28 \mathrm{~nm}$ in lawsonate and phthiocolate and by $65-66 \mathrm{~nm}$ in juglonate and plumbaginate. The shift in Sm-PH is very small as compare to other chelates. The third intense band attributed to $n \rightarrow \pi *$ transition in all the ligands show a significant change in its position, shape and intensity as a result of chelation. The $n \rightarrow \pi^{*}$ transitions are normally expected in visible region $(380-800 \mathrm{~nm})$ which is also important for ligand field spectra originated from $\mathrm{f}-\mathrm{f}$ transitions[21]. This band becomes broad with a large shift to higher wavelength.After chelation a large shift in Sm-LW and Sm-PH is of order of (300-332 nm) is seen while in SmJU and Sm-PL it is of order of (170-190 nm).The shifting of band in Lawsonate and phthiocolate is greater than in respective juglonate and plumbagin. Since all ligands are powerful donors and shifting at or above around $600 \mathrm{~cm}^{-1}$, this broad band is attributable to overlapping of $\mathrm{n} \rightarrow \pi^{*}$ transitions in the ligands, $\mathrm{f}-\mathrm{f}$ transitions within the metal and ligand to metal charge transfer in the chelates.

\section{Antimicrobial Activity Of Ligands And Chelates}

Antimicrobial activity of similar hydroxy 1,4 naphthoquinones and their oxime derivatives with some lanthanide metals such as $\mathrm{Ho}(\mathrm{III}), \mathrm{Er}(\mathrm{III}), \mathrm{Yb}(\mathrm{III})$ are reported by Jagtap etal and khandagale etal[17-20] while Varpe[21] has studied the activities of $\mathrm{Y}(\mathrm{III}), \mathrm{Eu}(\mathrm{III})$ and $\mathrm{Tb}(\mathrm{III})$ chelates of juglone derivatives. In this communication comparison of the activities of isomeric pairs of the selected juglones and their Sm(III) chelates is done.

\subsection{Materials and Methods:}

\subsubsection{Microorganisms and compounds:}

The antimicrobial investigations of Sm(III) chloride, lawsone,juglone, phthiocol, plumbagin and their chelates with Sm(III) were carried out against two Gram negative bacteria i.e Escherichia coli (NCIM - 2065) and Klebsiella pneumoniae (NCIM-2706) and three Gram positive bacterias which are Bacillus subtilis (NCIM - 2063), Micrococcus luteus (NCIM-2169), Staphylococcus aureus (NCIM - 2079) and These were obtained from National collection of Industrial Microorganisms division of National Chemical Laboratory, Pune. Metal salt $\mathrm{SmCl}_{3} \cdot 6 \mathrm{H}_{2} \mathrm{O}$ purchased by Aldrich was used for comparative purpose of antimicrobial activities. Well diffusion method was employed for the measurement of the activities. The effect of chelation and effect ring isomerism on the selected compounds is studied in the present work. 


\subsubsection{Concentration of compounds under test:}

The compound was tested for three concentrations $1 \mathrm{mg} / \mathrm{ml}, 1.5 \mathrm{mg} / \mathrm{ml}, 2 \mathrm{mg} / \mathrm{ml}$ dissolved in DMSO for compounds showing significant activity while the concentrations were increased further to $2.5 \mathrm{mg} / \mathrm{ml}, 3 \mathrm{mg} / \mathrm{ml}$, $3.5 \mathrm{mg} / \mathrm{ml}$ dissolved in DMSO for compounds not showing activity at lower concentrations. The activities at these various concentrations are summerized in Table- 4 . The concentration $(1.5 \mathrm{mg} / \mathrm{ml})$ at which all ligands and all chelates show significant activity are taken for the comparison and the results are presented in Table-5.

\subsubsection{Experimental Procedure:}

Fresh cultures of the bacteria organisms are taken. Suspension of the organisms was prepared in sterile peptone water. Prepared suspension was aseptically seeded in Nutrient Agar for bacterial cultures. Seeded agar was poured in sterile petriplates. After cooling, four wells of $8 \mathrm{~mm}$ diameter were bored in each plate. Each well was marked with the sample name and with the help of micropipette, $0.1 \mathrm{ml}$ of sample dilution was added in respective well. $(0.1 \mathrm{ml}$ of sample dilution correspond to $500 \mu \mathrm{g}$ Concentration per well). The bacterial plates were incubated at $37^{\circ} \mathrm{C}$ for $48 \mathrm{hrs}$.After incubation the organisms which are sensitive are inhibited by the test sample and inhibition zone is developed. The diameters of these inhibition zones were measured in mm. The antimicrobial activity in the present work is expressed in terms of circular zone inhibition areas $\left(\mathrm{mm}^{2}\right)$ calculated from $\pi r^{2}$ (where $r=$ radius i.e. 0.5 diameter) which is convenient for comparative purpose as proposed by Kulkarni.

\subsection{Results and discussion of antimicrobial activity:}

\subsubsection{Antimicrobial Activity of the Metal Salt and ligands:}

The activity of Samarium chloride is zero against all five microorganisms. Among four selected ligands, lawsone and phthiocol show MIC for the concentration, $1.5 \mathrm{mg} / \mathrm{ml}$ for all five microorganisms while juglone and plumbagin show MIC for $1 \mathrm{mg} / \mathrm{ml}$ for all five microorganisms. Therefore in general Juglone and Plumbagin exhibit greater activity as compared to Lawsone and Phthiocol for selected bacteria. For comparing activity within five organisms $1.5 \mathrm{mg} / \mathrm{ml}$ concentration is considered where all four ligands show considerable activity. The effect of chelation with samarium is also studied for the same concentration. The results are expressed through bar diagram (Fig-4). The ligand Plumbagin (conc.1.5 mg/ml) shows highest activity against all five selected bacteria where activity against $E$. coli is maximum. On the contrary ligand lawsone shows least activity against $M$. luteus among all ligands.

It is notable that the area of inhibition zone against Gram negative bacteria $(E$. coli and $K$. pneumoniae) are found to be greater as compared to that against Gram positive bacteria (B. subtilis, M. luteus and S. aureus) for Lawsone and Juglone. Phthiocol and Plumbagin do not exhibit such uniform trends for Gram positive and Gram negative bacteria.

\subsubsection{Antimicrobial Activity of the Sm (III) Chelates and effect of ring isomerism:}

The juglone and plumbagin chelates of $\mathrm{Sm}$ (III) show significant activity against selected microorganisms which is found to be reduced as a result of chelation as compared to original ligands. The activity of other two ligands, lawsone and phthiocol is totally diminished after chelation with Sm(III). Comparison of the antimicrobial activities of Sm-JU and Sm-PL, for all five microorganisms clearly shows that their activities are remarkably different from each other due to methyl substitution on Plumbagin. Sm-PL shows greater activity as compared to Sm-JU. Rahmoun etal [31] have showed that, the free keto groups at 1,4 position on naphthoquinone enhanced their bioactivity. In general the $\mathrm{OH}$ group on the ring increases the activity but when present at C-2 position decreases the activity as seen in lawsone and phthiocol. Ambrogi etal and bradnelli etal $[5,32]$ have showed that presence of electron donating groups such as methyl group at positions 2 or 3 on 1,4 naphthoquinones may enhance their antimicrobial activity as observed in plumbagin. These groups enhance hydrogen bonding, allowing stronger binding at its site of action. Therefore the strength of the activity is also related to the strength of hydrogen bonding [33].In the present study, Ligands, juglone and plumbagin having very strong intramolecular hydrogen bonding as compared to lawsone and phthiocol respectively results in greater antimicrobial activity. Similar trend is maintained for the isomeric metal chelates of juglone and plumbagin. The most notable observation is that, six membered Sm-JU and Sm-PL show greater activity against selected Gram negative bacteria as compared to Gram positive bacteria indicating the effect of ring size on the activity. Sm-PL shows highest activity against E. coli $\left(530.66 \mathrm{~mm}^{2}\right)$. It is maximum even at concentration $1 \mathrm{mg} / \mathrm{ml}\left(452.16 \mathrm{~mm}^{2}\right)$. Therefore this activity is likely to be predominant even at lower concentrations, for which further study is necessary. The results are summarized in Table no.5 and Fig-4. 
Table 4. Comparison of the Antimicrobial Activity of the Isomeric juglones and it's Chelates with Sm(III) at Different Concentrations.

\begin{tabular}{|c|c|c|c|c|c|c|c|c|c|c|c|}
\hline \multirow{2}{*}{$\begin{array}{l}\text { Compou } \\
\text { nds }\end{array}$} & \multirow{2}{*}{$\begin{array}{c}\text { Conc. } \\
\text { Mg/ml. }\end{array}$} & \multicolumn{2}{|c|}{ E. coli } & \multicolumn{2}{|c|}{ K. pneumoniae } & \multicolumn{2}{|c|}{ B. subtilis } & \multicolumn{2}{|c|}{ M. luteus } & \multicolumn{2}{|c|}{ S. aureus } \\
\hline & & $\mathrm{A}$ & B & A & B & $\mathrm{A}$ & B & $\mathrm{A}$ & B & $\mathrm{A}$ & B \\
\hline DMSO & $\begin{array}{ll}-- \\
\end{array}$ & --- & --- & $\begin{array}{ll}-- \\
\end{array}$ & $\begin{array}{ll}--- \\
\end{array}$ & $\begin{array}{ll}-- \\
\end{array}$ & --- & $\begin{array}{ll}-- \\
\end{array}$ & --- & --- & $\begin{array}{ll}-- \\
\end{array}$ \\
\hline \multirow{2}{*}{$\begin{array}{l}\mathrm{SmCl}_{3} .6 \\
\mathrm{H}_{2} \mathrm{O}\end{array}$} & $1.0 / 1.5 / 2.0$ & --- & --- & --- & $\begin{array}{ll}-- \\
\end{array}$ & --- & $\begin{array}{ll}-- \\
\end{array}$ & --- & --- & --- & --- \\
\hline & $2.5 / 3.0 / 3.5$ & $-\cdots$ & --- & --- & ---- & --- & --- & --- & --- & --- & --- \\
\hline \multirow[t]{3}{*}{ LW } & 1.0 & 13 & 132.66 & 13 & 132.66 & 10 & 78.5 & 10 & 78.5 & 10 & 78.5 \\
\hline & 1.5 & 18 & 254.34 & 17 & 226.86 & 11 & 94.985 & 14 & 153.86 & 12 & 113.04 \\
\hline & 2.0 & 18 & 254.34 & 19 & 283.38 & 15 & 176.62 & 15 & 176.62 & 16 & 200.96 \\
\hline \multirow[t]{2}{*}{ Sm-LW } & $1.0 / 1.5 / 2.0$ & --- & --- & $\begin{array}{ll}-- \\
\end{array}$ & ---- & $\begin{array}{ll}-- \\
\end{array}$ & --- & $\begin{array}{ll}-- \\
\end{array}$ & --- & --- & --- \\
\hline & $2.5 / 3.0 / 3.5$ & --- & --- & --- & --- & --- & --- & --- & --- & --- & --- \\
\hline \multirow[t]{3}{*}{$\mathrm{JU}$} & 1.0 & 18 & 254.34 & 16 & 200.96 & 15 & 176.62 & 14 & 153.86 & 15 & 176.625 \\
\hline & 1.5 & 18 & 254.34 & 16 & 200.96 & 15 & 176.25 & 14 & 153.86 & 15 & 176.625 \\
\hline & 2.0 & 18 & 254.34 & 16 & 200.96 & 16 & 200.96 & 14 & 153.86 & 15 & 176.625 \\
\hline \multirow[t]{3}{*}{ Sm-JU } & 1.0 & 13 & 132.66 & 14 & 153.86 & 14 & 153.86 & 17 & 226.86 & 14 & 153.86 \\
\hline & 1.5 & 14 & 153.86 & 15 & 176.65 & 15 & 176.62 & 17 & 226.86 & 15 & 176.62 \\
\hline & 2.0 & 14 & 153.86 & 16 & 200.96 & 15 & 176.62 & 17 & 226.86 & 15 & 176.62 \\
\hline \multirow[t]{3}{*}{$\mathrm{PH}$} & 1.0 & 14 & 153.86 & 12 & 113.04 & 13 & 132.66 & 10 & 78.5 & 10 & 78.5 \\
\hline & 1.5 & 16 & 200.96 & 12 & 113.04 & 13 & 132.66 & 14 & 153.86 & 11 & 94.98 \\
\hline & 2.0 & 16 & 200.96 & 13 & 132.66 & 14 & 153.86 & 14 & 153.86 & 11 & 94.98 \\
\hline \multirow[t]{2}{*}{ Sm-PH } & $1.0 / 1.5 / 2.0$ & --- & --- & --- & --- & --- & --- & --- & --- & --- & --- \\
\hline & $2.5 / 3.0 / 3.5$ & --- & --- & --- & --- & --- & --- & --- & --- & --- & --- \\
\hline \multirow[t]{3}{*}{ PL } & 1.0 & 34 & 907.46 & 25 & 490.62 & 26 & 530.66 & 26 & 530.66 & 25 & 490.62 \\
\hline & 1.5 & 36 & 1017.3 & 25 & 490.62 & 26 & 530.66 & 26 & 530.66 & 25 & 490.62 \\
\hline & 2.0 & 36 & 1017.3 & 26 & 530.66 & 27 & 572.26 & 26 & 530.66 & 25 & 490.62 \\
\hline \multirow[t]{3}{*}{ Sm-PL } & 1.0 & 24 & 452.16 & 12 & 113.04 & 13 & 132.66 & 14 & 153.86 & 13 & 132.66 \\
\hline & 1.5 & 26 & 530.66 & 17 & 226.86 & 16 & 200.96 & 16 & 200.96 & 16 & 200.96 \\
\hline & 2.0 & 27 & 572.26 & 20 & 314 & 17 & 226.86 & 19 & 283.38 & 18 & 254.34 \\
\hline
\end{tabular}

A: $\quad$ Diameter $(\mathrm{mm})$

B: $\quad$ Area $\left(\mathrm{mm}^{2}\right)$

Table-5 Antimicrobial activities of Isomeric Juglones and their Sm (III) Chelates at Conc. 1.5mg/ml.

\begin{tabular}{|c|c|c|c|c|c|}
\hline \multirow[t]{2}{*}{ Compounds } & \multicolumn{5}{|c|}{ Circular area of inhibition zone $\left(\mathrm{mm}^{2}\right)$} \\
\hline & E. coli & K. pneumoniae & S. aureus & B. subtilis & M. luteus \\
\hline DMSO & --- & --- & --- & $\begin{array}{ll}--- \\
-\end{array}$ & --- \\
\hline $\mathrm{SmCl}_{3} \cdot 6 \mathrm{H}_{2} \mathrm{O}$ & --- & --- & --- & --- & --- \\
\hline LW & 254.34 & 226.86 & 113.04 & 94.985 & 153.86 \\
\hline Sm-LW & --- & --- & --- & ---- & --- \\
\hline $\mathrm{JU}$ & 254.34 & 200.96 & 176.625 & 176.25 & 153.86 \\
\hline Sm-JU & 153.86 & 176.65 & 113.04 & 78.5 & 94.985 \\
\hline $\mathrm{PH}$ & 200.96 & 113.04 & 94.98 & 132.66 & 153.86 \\
\hline Sm-PH & --- & --- & --- & ---- & --- \\
\hline $\mathrm{PL}$ & 1017.3 & 490.62 & 490.62 & 530.66 & 530.66 \\
\hline Sm-PL & 530.66 & 226.86 & 200.96 & 200.96 & 200.96 \\
\hline
\end{tabular}

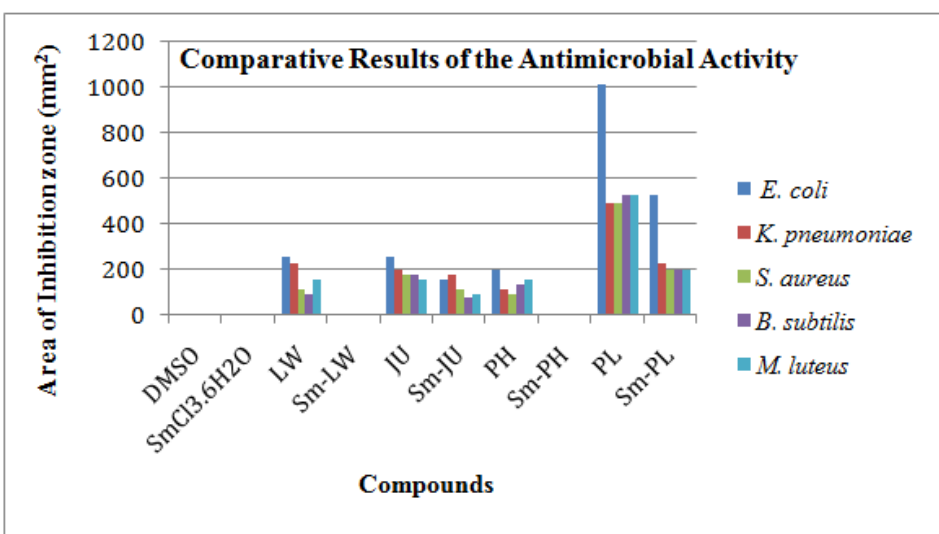

Fig.-4 Bar Diagram for Comparison of the Antimicrobial Activity of Isomeric Juglones and its Chelates with Sm(III) (Conc. $1.5 \mathrm{mg} / \mathrm{ml})$ 


\section{Conclusion}

Comparative study of Sm(III) chelates of Lawsone, juglone, phthiocol and plumbagin from spectral study indicates in that general six membered juglone and plumbagin chelates are thermodynamically more stable than five membered lawsone and phthiocol chelates. Notable large shifting of band in the electronic spectra of the Sm(III) chelates could be due to overlapping of $n \rightarrow \pi^{*}$ transitions,f-f transitions and ligand to metal charge transfer in chelates which is greater for six membered chelates as compared to five membered chelates. Greater shifting in Sm(III) phthiocolate as compare to lawsonate could be due to methyl substitution on the ring.Remarkable activity is shown by $\mathrm{Sm}$ (III) plumbaginate and juglonate which is greater for selected Gram negative bacteria than Gram positive bacteria while activity of respective five membered lawsonate and phthiocolate is lost indicating the effect of ring isomerism on these chelates.

\section{Acknowledgements}

Authors are thankful to University Grant Commission, Delhi for providing financial assistance as major research project.They are equally thankful to Prof. Dr. S.S. Kadam, Vice Chancellor, Bharati Vidyapeeth Deemed University,Pune, Principal K.D. Jadhav,Y.M. College,Pune, for providing necessary facilities and constant encouragement. Authors are also thankful to Dr. P.S. Khandagale for their valuable suggestions.

\section{References}

[1] R.H. Thomson, Naturally Occuring quinones $2^{\text {nd }}$ Ed (Academic press, New York 1971)

[2] Mrudula P Wadekar,Monali S. Itkar, Pritamkumar Shinde, B.L. Khade, Spectral, XRD and antimicrobial studies on isomeric chelates of Magnesium (II) and Calcium II) with phthiocol and plumbagin, International journal of chemical sciences, ,3(11), 2012,1606-1610

[3] S.B.Padhye and B.A. Kulkarni, Evidence for the hydrogen bonding in some hydroxylated naphthoquinones by adsoption chromatography, Chromatographia, 8(7), 1975, 352-353.

[4] N.R. Dhumal, A.V. Todakari, S.Y. Rane, S.P. Gejji, Hydrogen bonding motif in 2-hydroxy naphthoquinone, Theoretical chemistry accounts, 113(3), 2005, 161-166.

[5] Ambrogi V, Artini D, Carneri DE, Castellino S, Dradi E, Longemann W, Meinardi G, DI Somma M, Tosolini G, Studies on the antibacterial and antifungal properties of 1,4 naphthoquinones,Br.J.Pharmacol.,40,1970,871-880.

[6] S.H. Bhosale, S.L. Bhodhankar, M.B. Kulkarni, B.A. Kulkarni, Pharmacological studies of isomeric juglones on the isolated frog heart.,Indian journal of pharmacology, 1999, 31, 222-224.

[7] Peter Babula, Voje ch Adam, Rane Kizek, Zdene Sladky, Ladislav Have,naphthoquinone as allelochemical triggers of programmed cell deth, Enviromental and Experimental Botony ,65,2009, 330-337.

[8] S.Magdum, S. Banergee, G.P.Kalena, a Banergi, Chemosterilant activity of naturally occurring quinines and their analogs in the red cotton bugs, Dysdercus koenigil (Het., pyrrhocoridae), Journal of Applied Entomology, 125(9),8 ,2001, 589-596.

[9] Subhash Padhye,Prasad Dandawate, Mujabid Yusuf,Aamir Ahmad and Fazlul H. Sarkar, Prespectives on medicinal properties of Plumbagin and its analogs.,Medicinal Research Reviews.DOI 10.1002/med.1-28.

[10] David A. Evans, Alexander R. Muchi, Rainer Stuermer, Samarium(III)-Catalyzed Hydroboration of Olefins with Catecholborane. A General Approach to the Synthesis of Boronate Esters. J.Org.Chem.,1993,58, 5307-5309.

[11] Shipeng Wen, Xiaoping Zhang, Shui hu, Liqun Zhang, Li Liu., Influence of in-situ reaction on luminescent properties of samariumcomplex/hydrogenated acrylonitrile-butadiene composites., Polymer, 50, 2009, 3269-3274.

[12] S.Santhi and C.G. Radhakrishnan Namboori, Synthesis, Characterization and Antimicrobial Activity of Schiff Base Ligand Complexes of Sm(III), Gd(III) and Dy(III) ions, International Journal of ChemTech Research,(5)4, 2013,1750-1755.

[13] Waleed Mahmoud Al Momani, Ziyad Ahmed Taha, Abdulaziz Mahmoud Ajlouni,Qasem Mohammad Abu Shaqra,Muaz Al Zouby ,A Study of in vitro antibacterial activity of lanthanides complexes with a tetradentate Schiff base ligand, Asian pac J. Trop. Biomed., 3(5), 2013, 367-370.

[14] Irena Kostova and Tvetanka Stefanova, Synthesis, characterization and cytotoxic/cytostatic activity of Sm(III) and Gd(III) complexes,Journal of Coordination Chemistry, (62)19, 2009, 3187-3197.

[15] Irena Kostova, Georgi Momekov,and Peya Stancheva, New samarium(III), Gadolinium(III), and Dysprosium(III) Complexes of Coumarin-3-Carboxylic Acid as Antiproliferative Agents, Metal Based Drugs, 2007, article ID 15925,8pages, doi: $10,1155 / 2007 / 15925$.

[16] V.D. Kelkar, H.R.Gholap, R.R. Gokhale, M.B. Kulkarni, Synthesis and characterization of Ho(III) chelates of some juglones., Indian journal of chemistry, 37A,1998, 915-917.

[17] S.B.Jagtap,S.G. Joshi, G.M. Litake, V.S.Ghole and B.A. Kulkarni. C-3 Substituted Lawsonemonoximates of Holmium (III) Synthesis, Characterization and Antimicrobial activity,Metal-Based Drugs.7(3),2000, 147-150.

[18] S.B.Jagtap,R.C. Chikate ,O.S.Yemul, R.S.Ghadage and B.A. Kulkarni,Thermal,Spectral and Magnetic properties of 2-Hydroxy 1,4-naphoquinone Monoximates of Ho(III), Er(III) and Yb(III). Journal of Thermal of Analysis and Calorimetry, 78, 2004, $251-262$.

[19] S.B.Jagtap,N.N.Patil, B.P. Kapadnis and B.A. Kulkarni, Characterization and Antimicrobial activity of Er(III) Complexes of -3 Substituted 2-Hydroxy-1,4-Naphthalenedione-1-oxime Derivatives.Metal Based drugs,8(3),2001, 159-164.

[20] Prasad Khandagale,Rajeev Chikate,S.B.Joshi, B.A.Kulkarni.Binuclear lanthanide complexes of 2,3-dihydroxy-1,4-naphthoquinone, Journal of Alloys and Compounds. 392,2005,112-119.

[21] D.K. Varpe, Isomeric juglonates of Yttrium, Europium and Terbium. Ph.D thesis, University of Pune, Pune(India), 1996.

[22] Mingxiong Tan, Xujian Luo, Yungiong Gu, Gongcong Lu, The Interaction of cytotoxic Sm(III) complex of Plumbagin with bovine serum albumin.Advanced Materials Research, 634-638, 2013, 1380-1383.

[23] Chen ZF,Tan MX,Liu YC,Peng Y, Wang HH,Liu HG, Liang H., Synthesis, Characterization and preliminary cytotoxicity evaluation of five lanthanide(III)- Plumbagin complexes. J. Inorg Biochem. 105(3) , 2011, 426-34.

[24] Radt F, Elsevier's encyclopaedia of organic chemistry, SeriesIII,12B(Elsevier, Amsterdam,1952).

[25] Fieser LF, Convenient procedures for the preparation of antihemorrhagic compounds, J. Biol. Chem., 133, 1940, $391-396$. 
[26] Joshi CR, Kulkarni PL, Varpe DK, Kulkarni BA Thermal and spectral studies of some rare earth chelates of chlorojuglone antibacterials. Thermochim. Acta. 190, 1991, 285-290.

[27] Sartori G,Furlani C, Damiani A, On the problem of the vibrational frequencies of water in complexes.J. Inorg. Nucl. Chem. 8, $1958,119-125$.

[28] Kanase D.G., Kulkarni(Wadekar) M., Kadam S.S., Kelkar V.D., Synthesis, Spectral and XRD studies on isomeric chelates of strontium(II) barium(II) with phthiocol and plumbagin, Asian J. Chem.,16(3-4), 2004, 1630-1636.

[29] Kodolikar J.G. Studies in ring isomeric $\mathrm{UO}_{2}$ (II) and Th(IV) complexes of some juglones and C-3 substituted lawsone monoximates of U(IV).Ph.D thesis of University of Pune,Pune (India), 1996.

[30] Singh, Ogata RT, Moore RE, Chang CWJ, Scheuer PJ, Electronic spectra of substituted naphthoquinones, Tetrahedron, 24(18), $1968,6053-6073$

[31] Rahmoun Nadjib Mohammed, Zahia Buocheri-Atmani, Mohammed Benabdallah, Kebir Boucherit, Didier Villemin, Noureddine Choukchou-Braham, Antimicrobial activities of the Henna extract and some synthetic naphthoquinone derivatives., American Journal of Medical and Biological Research, 2013, (1)1, 16-22.

[32] Brandelli A, Delmar B, Martinelli M, Stefani V, Gerbas EG, Antimicrobial activity of 1,4 naphthoquinones by metal complexation, Braz. J. Pharm. Sci., 40(2) ,2004, 248-253.

[33] Gafner, S., Wolfender, J.L., Nianga, M., Stoceckli-Evans H and Hostettmann, K. Antifungal and antibacterial naphthoquinones from Newbouldia leavis roots., Phytochemistry, 42(5), 1996., 1315-1320. 